\title{
Simulation Study on Train-Induced Vibration Control of a Long-Span Steel Truss Girder Bridge by Tuned Mass Dampers
}

\author{
Hao Wang, ${ }^{1,2}$ Tianyou Tao, ${ }^{1,2}$ Huaiyu Cheng, ${ }^{1,2}$ and Xuhui He \\ ${ }^{1}$ Key Laboratory of C\&PC Structures of Ministry of Education, Southeast University, Nanjing 210096, China \\ ${ }^{2}$ School of Civil Engineering, Southeast University, Nanjing 210096, China \\ ${ }^{3}$ School of Civil Engineering, Central South University, Changsha 410082, China
}

Correspondence should be addressed to Hao Wang; wanghao1980@seu.edu.cn

Received 15 July 2014; Revised 8 October 2014; Accepted 9 October 2014; Published 16 December 2014

Academic Editor: Ting-Hua Yi

Copyright (C) 2014 Hao Wang et al. This is an open access article distributed under the Creative Commons Attribution License, which permits unrestricted use, distribution, and reproduction in any medium, provided the original work is properly cited.

\begin{abstract}
Train-induced vibration of steel truss bridges is one of the key issues in bridge engineering. This paper talks about the application of tuned mass damper (TMD) on the vibration control of a steel truss bridge subjected to dynamic train loads. The Nanjing Yangtze River Bridge (NYRB) is taken as the research object and a recorded typical train load is included in this study. With dynamic finite element (FE) method, the real-time dynamic responses of NYRB are analyzed based on a simplified train-bridge time-varying system. Thereinto, two cases including single train moving at one side and two trains moving oppositely are specifically investigated. According to the dynamic characteristics and dynamic responses of NYRB, the fourth vertical bending mode is selected as the control target and the parameter sensitivity analysis on vibration control efficiency with TMD is conducted. Using the first-order optimization method, the optimal parameters of TMD are then acquired with the control efficiency of TMD, the static displacement of Midspan, expenditure of TMDs, and manufacture difficulty of the damper considered. Results obtained in this study can provide references for the vibration control of steel truss bridges.
\end{abstract}

\section{Introduction}

As one of the most important infrastructures, railway bridge performs the role that maintains the transportation between two separated locations to overcome the space and terrain limitations. Due to the large gravity of trains and the requirement for bridge span, railway bridges usually demand much higher stiffness than highway bridges. On account of the superior characteristics of steel material and truss structure, the steel truss bridge exhibits the capability to cross wide rivers or canyons with light weight and enough stiffness to cope with train loads, vehicle loads, or both. Although the existing steel truss bridge has been equipped with sufficient capability for structural safety subjected to train loads, field tests in China, Japan, and Europe have indicated obvious dynamic responses exceeding that anticipated on certain small and medium span railway bridges [1-3]. The theoretical investigations validate the contribution of structural resonance arising from the moving of trains with high speed to this phenomenon [4]. When the train moves on a steel bridge with a high speed, the train-induced vibrations of the steel truss bridge will lead to the deterioration of passengers' comfort, the fatigue of steel structural component, the decrease of traffic safety accompanied by damage to the tracks, and the augment of maintenance cost. Therefore, some effective measures need to be carried out to suppress the vibrations of steel truss bridge subjected to dynamic train loads.

Since the 1970s, the tuned mass damper (TMD) has been introduced to protect the civil structures from suffering vibration-induced major damage because of its lateral motions [5-9]. TMD is a classical engineering device which consists of a spring, a mass, and a viscous damper. The simple structure of TMD brings about its obvious virtues of economical costing and installation convenience. TMD is considered to be sensitive to the frequency variation of structures, but the viscous damper can broaden its effective frequency ranges [10]. The existing researches and applications have proved that the TMD is an efficient approach 
to attenuate undesirable vibrations of a vibrating system, and it has already been extensively studied and applied to suppress structural vibrations induced by wind, earthquakes, trains, and so forth. As some typical examples, the wind tunnel and theoretical analyses by $\mathrm{Xu}$ et al. [11] verified the effectiveness of TMD in suppressing wind-induced tall building motions. Using the perturbation solutions, formulas related to designing the TMD attached to the single-degreeof-freedom (SDOF) system for various types of loading were proposed by Fujino and Abe in 1993 [12]. Aiming to dissipate earthquake input energy, Wong [13] investigated the energy transfer process of TMD in improving the ability of inelastic structures.

Although TMD has been extensively studied or successfully implemented for suppressing vibrations of structures due to environmental loadings such as wind and earthquakes, only a few researches have been conducted on applications of TMD in reducing the vibrations of bridges due to train loads, and the existing researches are mainly focused on simply supported reinforced concrete bridges with moderate or small spans $[3,14-16]$. As for the long-span continuous steel truss girder bridge, the studies on vibration control of bridges subjected to dynamic train loads with TMD are fewer. The objective of this study is to apply TMDs with optimal parameters for suppressing vibrations of a steel truss bridge subjected to moving trains. With typical train axle loads, the parametric sensitivity analysis is conducted and the effectiveness of TMD for suppressing dynamic vibrations is examined based on a simplified train-bridge time-varying system. Taking account of the control efficiency, expenditure of TMDs, TMD-induced static displacement of the bridge, and the manufacturing difficulty of damping of different magnitude, an objective function for evaluating the control efficiency is proposed and the optimal parameters of TMD are finally determined with the first optimization method. The analytical procedure and results can provide references for the vibration control of steel truss bridge subjected to dynamic train loads.

\section{Simplified Train-Bridge Time-Varying System}

A bridge is possibly to suffer from different kinds of dynamic loads during its long-term service period, such as the vehicles, winds, and earthquakes. Compared with other dynamic loads acting on the bridge, the location of train loads on bridges is time-varying, which makes the dynamic characteristics of the train-bridge coupled system dependent on the location of train loads. Therefore, the resonance condition can only happen in a short moment and it is difficult to establish a clear correlation between the moving train loads and the bridge responses. To clearly identify the train-bridge time-varying system, some simplified models have already been proposed [17-21]. These simplified models provide the basis for further investigations on the train-bridge coupled system.

In this study, a broadly used simplified model proposed by Kriloff in 1905 [18] is adopted to simulate the train-bridge time-varying system. The loads induced by train moving at a constant speed are simplified as a series of concentrated forces moving at the same speed. These concentrated forces locate at the junctions of wheels and the track. Considering the difficulty in solving differential equations with variable coefficients, the inertia forces of the train are neglected during the analysis.

\section{Engineering Background}

3.1. Bridge Description. The Nanjing Yangtze River Bridge (NYRB), as shown in Figure 1, is a double-decked steel truss bridge across the Yangtze River. Since 1968, it has operated as a railway and highway combined bridge for 46 years. The upper deck of NYRB is employed as part of National Highway 104 in China with four lanes. The total width of the carriage way is $15 \mathrm{~m}$ accompanied by a $2.25 \mathrm{~m}$ wide walkway on each side. The lower deck of NYRB serves for railway transportation with a width of $14 \mathrm{~m}$. Two pairs of parallel seamless railway tracks are installed on the deck so that the trains can move in opposite directions simultaneously. The main bridge is the combination of three continuous girder bridges and a simply supported bridge with a total length of $1568 \mathrm{~m}$. Thereinto, three expansion joints are set at Piers 1, 4 , and 7 , respectively, to separate the three-span continuous girder bridges and the simply supported bridge. Each span of the continuous bridge is $160 \mathrm{~m}$ long and the length of the simply supported bridge is $128 \mathrm{~m}$. The main girder is composed of the steel truss structure with stiffening chord members. Each segment for the main girder is $8 \mathrm{~m}$ with a height of $16 \mathrm{~m}$ and connections between each segment are mainly rivet joints. In this paper, the three-span continuous girder bridge between Piers 7 and 10 near Nanjing will be taken as the research object.

3.2. Simplified Model of Dynamic Train Loads. The structural health monitoring system of NYRB [22] recorded a train moving at $70 \mathrm{~km} / \mathrm{h}$ to cross the Yangtze River. The train is composed of two locomotives and eighteen carriages, as shown in Figure 2. There are six axles on each locomotive and each axle weighs 22 tons which is evenly assigned to two wheels. All of the carriages work with four axles and each axle weighs 20 tons so that each wheel can transfer 10-ton weight to the bridge structure. In order to study the dynamic behaviour of the train-bridge time-varying system, the train herein is simplified as a series of moving concentrated forces with fixed intervals. The axle distance is detailed in Figure 2 and the unit for the distance is meter. The overall length of the train is 292 meters. In regard to the train loads, the concentrated forces are acquired by the axles loads multiplied by the gravitational acceleration of $9.8 \mathrm{~m} / \mathrm{s}^{2}$.

\section{Finite Element Model and Its Application}

4.1. Finite Element Model Based on ANSYS. NYRB is a truss structure with complicated features due to its various types of vertical and lateral connection systems and its main functions addressed to both railway and highway. The threespan continuous girder bridge contains 7690 elements and 30 


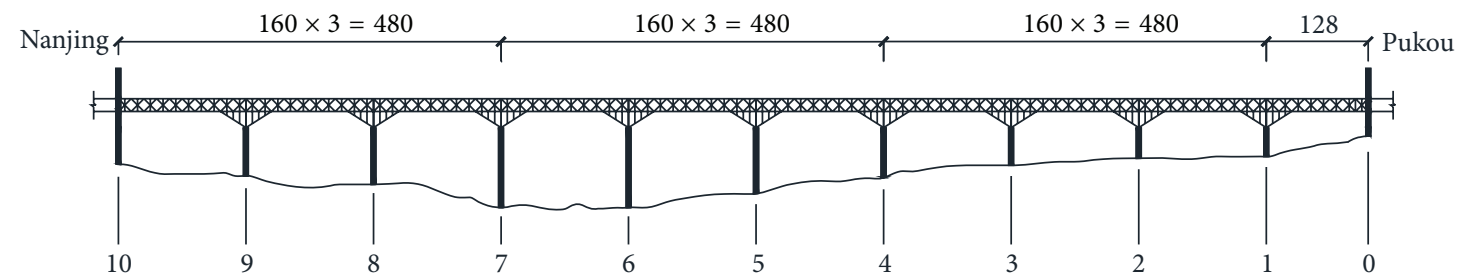

Figure 1: Layout of Nanjing Yangtze River Bridge (unit: m).

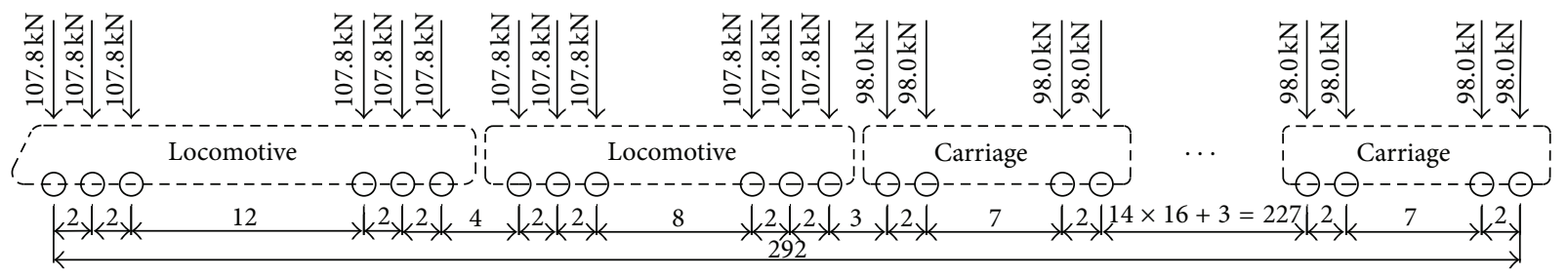

FIgURE 2: Layout of the train loads and axle distance.

types of sections. With appropriate simplification, a spatial FE model of NYRB is established based on ANSYS [23], as shown in Figure 3. The main truss rods, track beams, and lateral connection systems are modeled by spatial beam element (Beam 4). And the pavement on highway surface and seamless steel rail, which have little contribution to structural stiffness, are simulated by mass element (Mass 21) imposed on the corresponding nodes of the truss bridge girder. To facilitate the exertion of axial forces, the track beam is partially refined in the mesh generation. The vertical, lateral, vertical-rotational, and longitudinal-rotational DOFs (degrees of freedom) are restricted at the four supports $[24,25]$. In addition, the bearing between Side-span 1 and Midspan is restricted in longitudinal direction while the other directions are set free.

4.2. Dynamic Characteristics of NYRB. In order to acquire the natural frequencies and corresponding mode shapes of NYRB, a modal analysis is conducted and the first 200 modes are extracted with subspace iteration method. Table 1 lists the first 12 natural frequencies and corresponding characteristics. Among the first 12 structural modes, the lowest modal frequency is $1.0576 \mathrm{~Hz}$ which corresponds to symmetric vertical bending vibration of the whole bridge. The first lateral bending mode appears as the second structural mode of NYRB and this phenomenon reflects a relatively larger lateral stiffness than vertical stiffness existing in NYRB. All of the first three lateral bending modes exhibit the lateral vibration of only one span (Side-span 1, Midspan, or Side-span 2), which reveals the lateral vibration of each span has little influence on those of the other two spans. Similar to the lateral bending mode, the second and the third vertical bending mode shapes are the vibration of Side-span 1 and Side-span 2, respectively. The torsional vibration modes appear continuously from the seventh to the tenth structural mode. Specifically, the first three perform as symmetric or antisymmetric torsional vibration of the whole bridge accompanied by lateral bending vibration, while the fourth one performs as the torsional
TABLE 1: The first 12 natural frequencies and mode shapes of NYRB.

\begin{tabular}{|c|c|c|c|}
\hline Numbe & $\begin{array}{l}\text { Natural } \\
\text { r frequency } \\
(\mathrm{Hz})\end{array}$ & $\begin{array}{c}\text { Mode } \\
\text { direction }\end{array}$ & Characteristics of modes \\
\hline 1 & 1.0576 & V & $\begin{array}{l}\text { Symmetric vertical bending } \\
\text { vibration of the whole bridge }\end{array}$ \\
\hline 2 & 1.1937 & $\mathrm{~L}$ & $\begin{array}{l}\text { Lateral bending vibration of } \\
\text { Side-span } 1\end{array}$ \\
\hline 3 & 1.2040 & $\mathrm{~L}$ & $\begin{array}{l}\text { Lateral bending vibration of } \\
\text { Side-span } 2\end{array}$ \\
\hline 4 & 1.4140 & $\mathrm{~L}$ & $\begin{array}{l}\text { Lateral bending vibration of } \\
\text { Midspan }\end{array}$ \\
\hline 5 & 1.7649 & V & $\begin{array}{l}\text { Vertical bending vibration of } \\
\text { Side-span } 1\end{array}$ \\
\hline 6 & 2.1638 & V & $\begin{array}{l}\text { Vertical bending vibration of } \\
\text { Side-span } 2\end{array}$ \\
\hline 7 & 2.2736 & $\mathrm{~L}+\mathrm{T}$ & $\begin{array}{l}\text { Antisymmetric lateral bending } \\
\text { vibration of the whole bridge } \\
\text { accompanied by antisymmetric } \\
\text { torsional vibration }\end{array}$ \\
\hline 8 & 2.3728 & $\mathrm{~L}+\mathrm{T}$ & $\begin{array}{l}\text { Symmetric lateral bending } \\
\text { vibration of the whole bridge } \\
\text { accompanied by antisymmetric } \\
\text { torsional vibration }\end{array}$ \\
\hline 9 & 2.5164 & $\mathrm{~L}+\mathrm{T}$ & $\begin{array}{l}\text { Symmetric lateral bending } \\
\text { vibration of the whole bridge } \\
\text { accompanied by symmetric } \\
\text { torsional vibration }\end{array}$ \\
\hline 10 & 2.7352 & $\mathrm{~T}$ & Torsional vibration of Side-span 1 \\
\hline 11 & 2.8726 & $\mathrm{~V}$ & $\begin{array}{l}\text { Symmetric vertical bending } \\
\text { vibration of the whole bridge }\end{array}$ \\
\hline 12 & 3.2437 & $\mathrm{~V}$ & $\begin{array}{l}\text { Antisymmetric vertical bending } \\
\text { vibration of the whole bridge }\end{array}$ \\
\hline
\end{tabular}

vibration of Side-span 1. The fourth and the fifth vertical bending mode correspond to the eleventh and the twelfth 


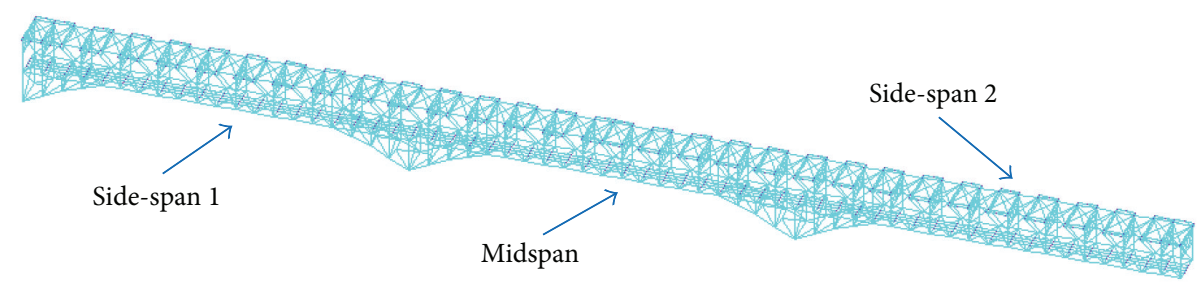

FIGURE 3: Spatial finite element model of NYRB.
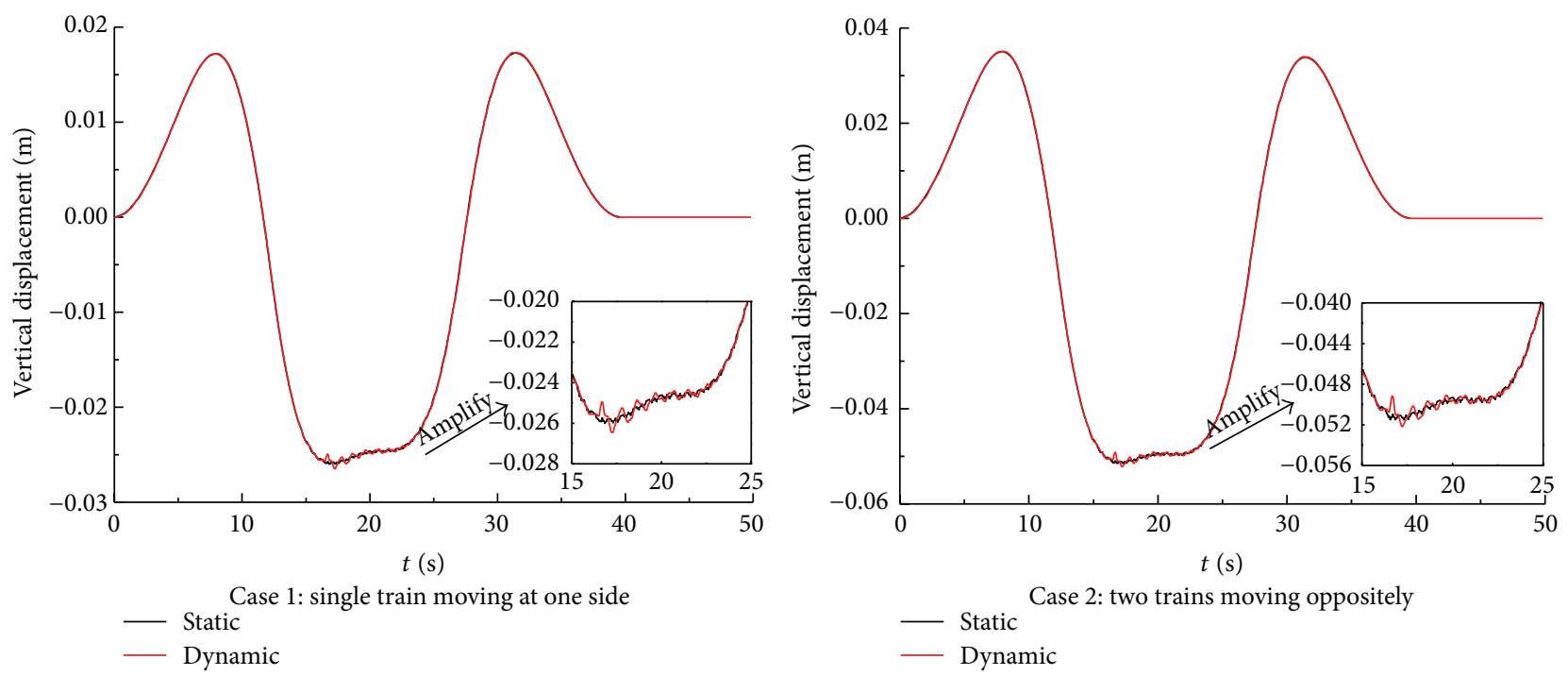

FIGURE 4: Vertical displacement in the middle of Midspan.

structural mode, respectively. Among them, the fourth one is the symmetric vertical bending vibration and the fifth one is the antisymmetric vertical bending vibration of the whole bridge. In the view of mode shapes, only the first and the fourth vertical bending modes dominate the vertical vibration of the Midspan while others have little influence.

4.3. Dynamic Responses of NYRB Excited by Train Loads. Considering the functions of NYRB, two cases including single train moving at one side and two trains moving oppositely are analyzed in the train-bridge time-varying system. Thereinto, the second case describes a situation that two trains set off from the two sides of NYRB simultaneously and the time phase difference is not included in this study. During the transient dynamic analysis by ANSYS, the full method with intact system matrix is utilized and the Newmark- $\beta$ technique is adopted to conduct the time integration. On account of the steel material employed in the construction of NYRB, the damping ratio of the whole structure is set as $2 \%$.

4.3.1. Displacement Responses of the Bridge Span. With transient analyses of the train-bridge time-varying system, the displacements in the middle of the spans are the most prominent. Table 2 lists the maximum displacement in the middle of each span of the two cases. Thereinto, the torsional displacement has been multiplied by half of the bridge deck width to unify the unit. As shown in Table 2, the vertical displacement is the most prominent while the lateral and torsional displacements are much smaller. However, the maximum vertical displacement of the two cases does not surpass 0.06 meters and it is much smaller than one-thousandth length of the main span. Hence, the small maximum vertical displacement of the bridge span under the actions of moving trains reflects the strong vertical stiffness of NYRB.

In order to reveal the difference of vertical displacement between static train loads and dynamic train loads, the displacement response of NYRB under static train loads is calculated. The static and dynamic vertical displacements in the middle of Midspan of the two cases are shown in Figure 4 . Since the train moves at a speed of $70 \mathrm{~km} / \mathrm{h}$, the train completely leaves the bridge after $42.79 \mathrm{~s}$. As for the vertical displacements induced by static train loads and dynamic train loads, there is little difference between them during the whole procedure except for the time duration from $15.02 \mathrm{~s}$ to $24.69 \mathrm{~s}$. At the moment of $15.02 \mathrm{~s}$, the train is just completely landing on the bridge. And at the time of $24.69 \mathrm{~s}$, the train begins to leave the bridge and the time of 24.69 s corresponds to the last moment that the whole train is on the bridge. During the time interval between $15.02 \mathrm{~s}$ and $24.69 \mathrm{~s}$, the dynamic vertical displacement is fluctuant. However, in this period the deviation between the static and dynamic vertical displacements is still small. The detailed difference among the 
TABle 2: Maximum displacement in the middle of each span (unit: $\mathrm{m}$ ).

\begin{tabular}{|c|c|c|c|c|c|c|}
\hline \multirow{2}{*}{ Case } & \multicolumn{3}{|c|}{ Case 1: single train moving at one side } & \multicolumn{3}{|c|}{ Case 2: two trains moving oppositely } \\
\hline & Side-span 1 & Midspan & Side-span 2 & Side-span 1 & Midspan & Side-span 2 \\
\hline Vertical & 0.0456 & 0.0260 & 0.0442 & 0.0522 & 0.0516 & 0.0498 \\
\hline Lateral & 0.0006 & 0.0015 & 0.0016 & 0.0008 & 0.0013 & 0.0019 \\
\hline Torsional & 0.0036 & 0.0032 & 0.0037 & 0.0034 & 0.000067 & 0.0037 \\
\hline
\end{tabular}

Note: the displacement in the table has subtracted the gravity-caused static displacement of the structure; the values in the table are the absolute values of maximum displacement.

time interval has been amplified in the lower right corner of each figure. The phenomenon above has similar features with the analytical results by Chatterjee et al. in 1994 [21]. Due to the small vertical displacements induced by dynamic train loads, the displacement cannot be chosen as the target to conduct vibration control analysis.

4.3.2. Acceleration Responses of the Bridge Span. An obvious difference between the static and the dynamic train actions is the excited acceleration response of the bridge structure by the dynamic train loads. The acceleration magnitude reflects the intensity of vibration of the whole structure, which is closely related to the deterioration of passengers' comfort, the decrease of traffic safety accompanied by damage to the tracks, and the augment of maintenance cost. The time histories of the acceleration responses in the middle of each span of two cases are shown in Figure 5.

As shown in Figure 5, the overall trend reveals that the amplitudes of both lateral and torsional acceleration are much smaller than that of vertical acceleration in each span. Compared to Case 1, the vertical acceleration of each span increases prominently in Case 2. In regard to lateral and torsional accelerations, the differences between the two cases are not consistent. In the middle of Side-span 1, the amplitudes of both lateral acceleration and torsional acceleration increase a little in Case 2 compared with those of Case 1. In the middle of Side-span 2, obvious peak accelerations occur in the lateral and torsional time histories of Case 2, and the peak accelerations occur near the point of $16.5 \mathrm{~s}$. As for Midspan, the lateral and torsional accelerations are counteracted to a large extent when two trains move oppositely on the bridge. The analysis above shows that the concentration should be paid to vertical acceleration of each span in this study.

In Case 1, the maximum vertical accelerations of Side-span 1, Side-span 2, and Midspan are $0.0520 \mathrm{~m} / \mathrm{s}^{2}$, $0.0668 \mathrm{~m} / \mathrm{s}^{2}$, and $0.1453 \mathrm{~m} / \mathrm{s}^{2}$, respectively. In Case 2, the maximum vertical accelerations of Side-span 1, Side-span 2, and Midspan are $0.1027 \mathrm{~m} / \mathrm{s}^{2}, 0.1509 \mathrm{~m} / \mathrm{s}^{2}$, and $0.3172 \mathrm{~m} / \mathrm{s}^{2}$, respectively. From the peak accelerations above, it is easy to find that the acceleration in the middle of Midspan is much larger than that of Side-span 1 and Side-span 2; all of the vertical accelerations especially in Case 2 are so prominent that some measures need to be employed to suppress the dynamic train-induced vibrations of the bridge.

The vertical acceleration time histories of each span in Figure 5 are transformed into PSD (power spectral density) with Welch transformation [26], as shown in Figure 6. Though the dynamic loads are different in the two cases, the frequency-domain features are similar. The PSDs indicate that the vibration energy of the two cases concentrates around an exciting frequency of $2.761 \mathrm{~Hz}$, which is in the neighborhood of the fourth vertical bending mode of NYRB. This phenomenon shows that the fourth vertical bending mode contributes most to the train-induced vibration of NYRB. Considering that the exciting frequency may be on the deviation of $2.761 \mathrm{~Hz}$ when the moving speed of the train changes, the fourth vertical bending mode is selected as the control mode in this study. Consequently, the TMD is designed to control the fourth vertical bending mode that dominates the vertical vibration responses of the train-bridge system.

\section{Analysis of the Vibration Control Effect of TMD}

5.1. Layout of TMDs on NYRB. For structures whose dynamic responses are dominated by one structural mode, the TMDs should be deposited near the amplitude of the corresponding mode shape. So the TMDs are attached to the center region of Midspan of NYRB, where the mode shape of the fourth vertical bending mode is the largest. For the nether deck of NYRB shown in Figure 7, there are four track beams symmetrically arranged in the inner side for the moving of trains and two structural beam elements in the outer side to serve for the whole structure. The transverse beams are utilized to strengthen the integrity of the bridge structure with an adjacent distance of 8 meters. In order to guarantee the simplicity of the loading path, each TMD is hung at the joint of the longitudinal beam and the transverse beam. And three transverse beams in the central region of Midspan are selected to install the TMDs; thus 18 TMDs in total are employed to conduct the vibration control of NYRB. The detailed layout of TMDs on NYRB can be seen in Figure 7, among which the red blocks represent the TMDs in Midspan.

5.2. Design Parameters for the TMD. The TMD is a device with a simple structure and explicit working mechanism. It is made up of a mass block and a spring as well as a damper. The main contents for designing a TMD are connected to the mass of the block, the stiffness coefficient of the spring, and the damping coefficient of the damper. Two mechanical parameters including the natural frequency and the damping ratio are related with the above three variables. According to the working mechanism of the TMD, the natural frequency of the TMD is determined as the same 

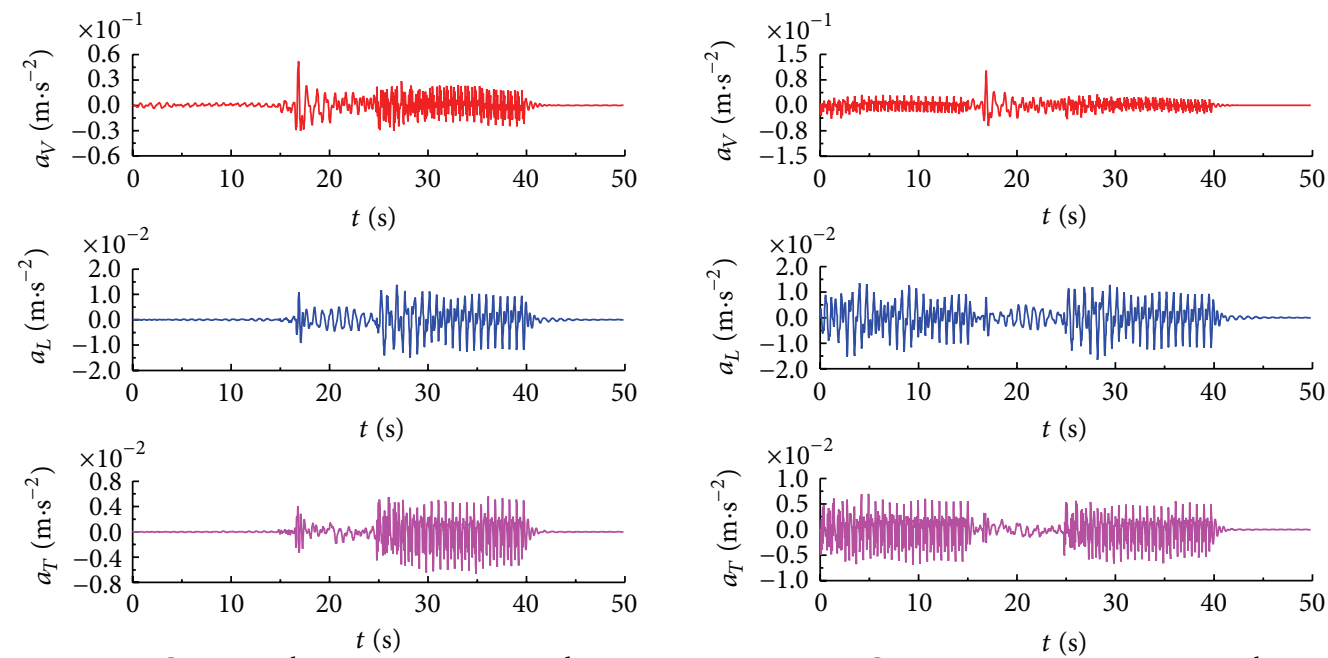

Case 1: single train moving at one side

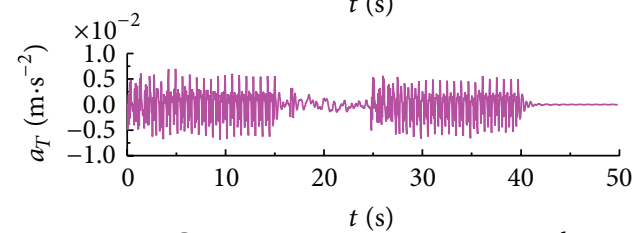

Case 2: two trains moving oppositely

(a) Side-span 1
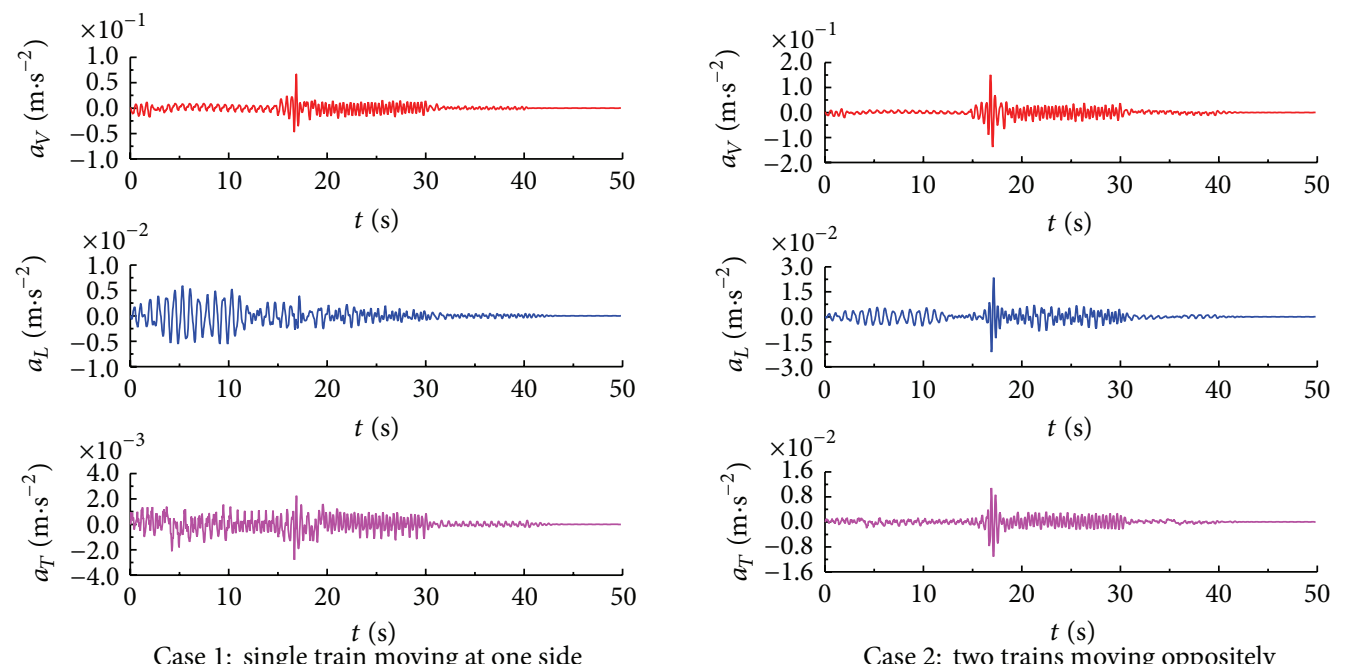

Case 2: two trains moving oppositely

(b) Side-span 2
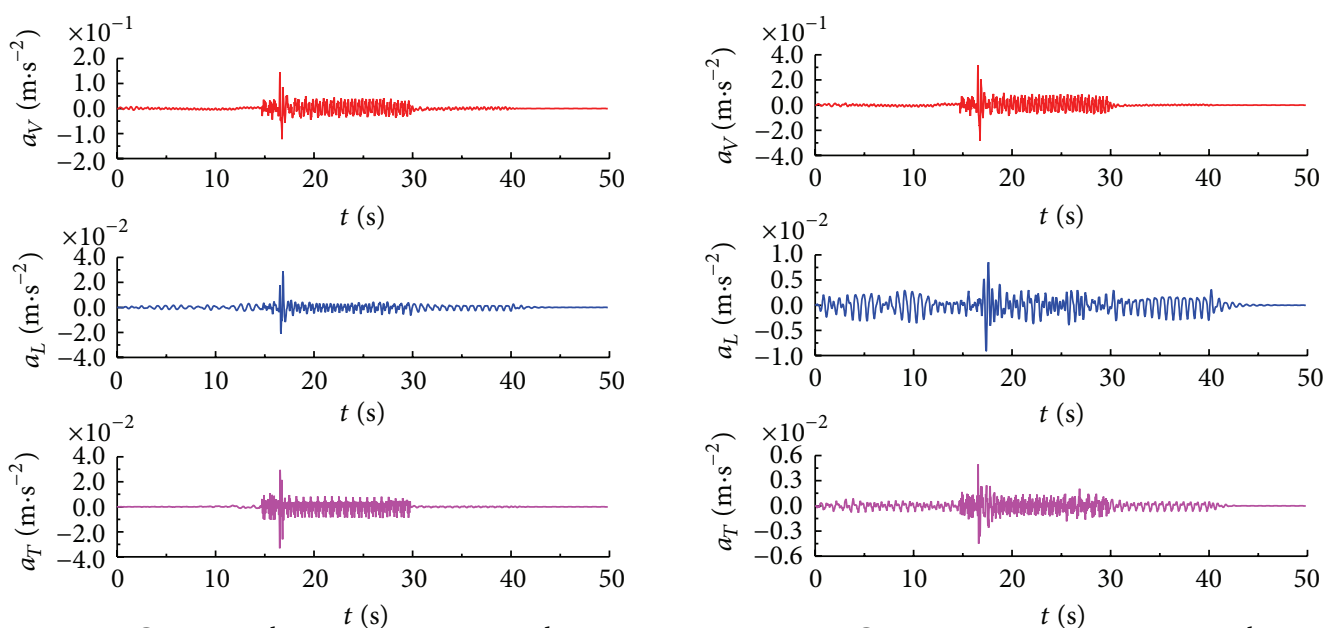

Case 1: single train moving at one side

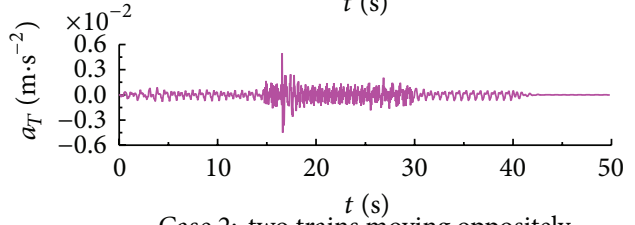

$t(\mathrm{~s})$
Case 2: two trains moving oppositely

_ Vertical acceleration _ Torsional acceleration

_ Lateral acceleration

— Vertical acceleration _ Torsional acceleration

_ Lateral acceleration

(c) Midspan

FIgURE 5: Time histories of the acceleration in the middle of each span. 

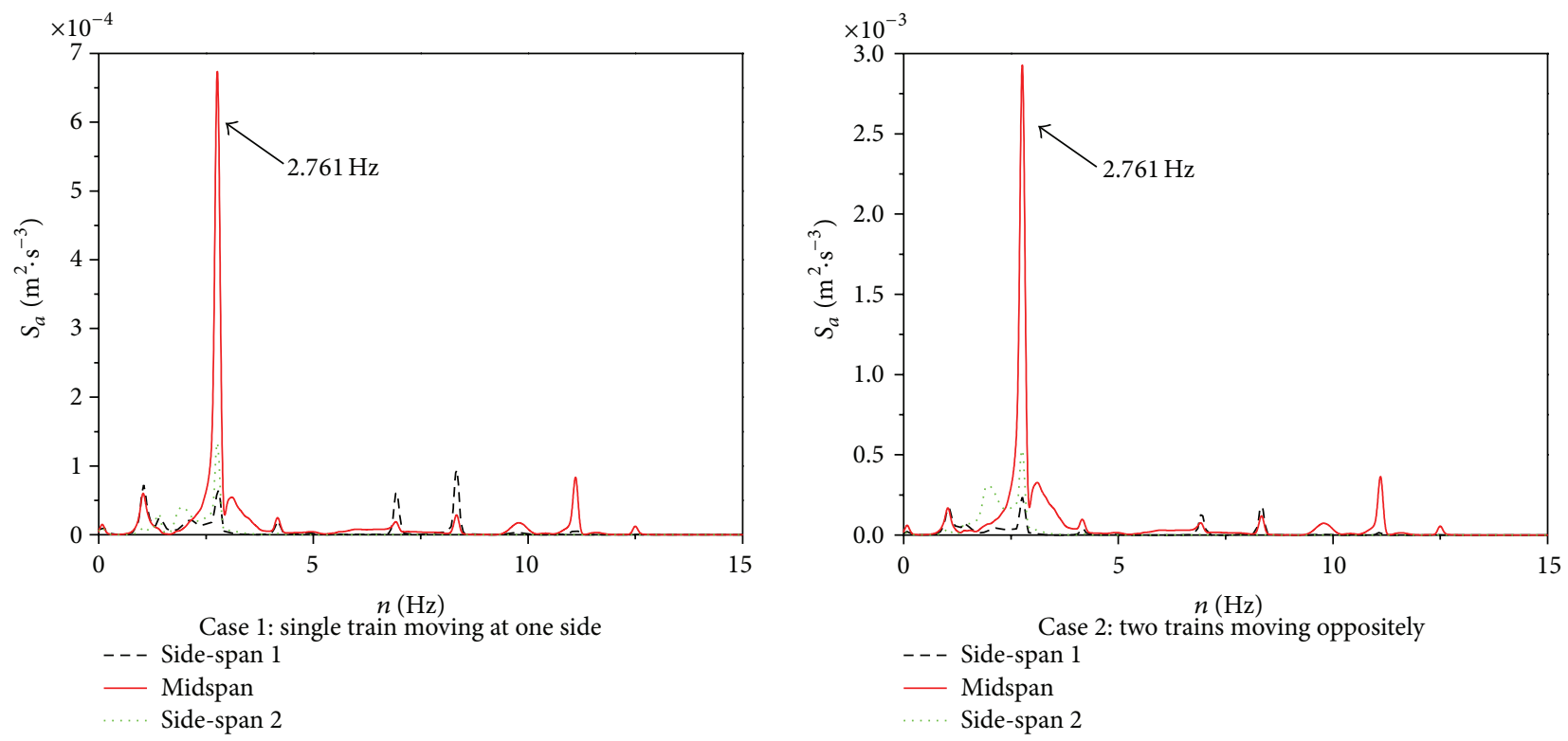

FIGURE 6: Power spectral density of vertical acceleration in the middle of each span.

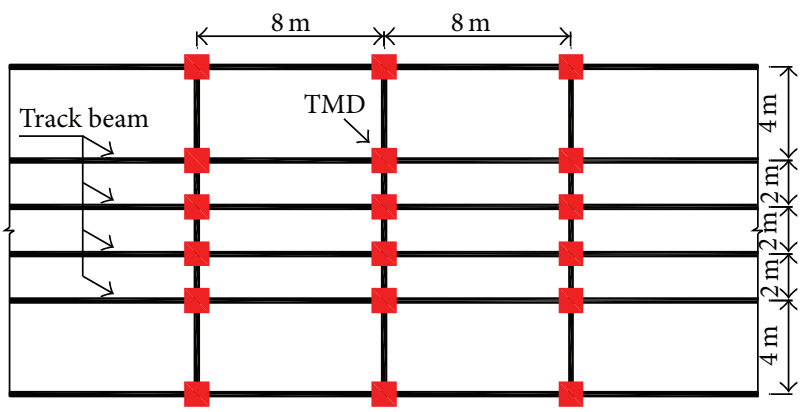

FIGURE 7: Layout of TMDs on the nether deck of NYRB.

with the frequency of the fourth vertical bending mode of NYRB. Meanwhile, the mass of a TMD has great influences on the vibration control efficiency. Therefore, the design parameters including the mass of the block and the damping ratio should be determined at first, while the other parameters can be determined when the two parameters are certain.

The stiffness coefficient of the spring in the TMD can be calculated by $[12,27]$

$$
k=f^{2} \cdot m,
$$

where $k=$ the stiffness coefficient of the spring, $m=$ the mass of the block, and $f=$ the natural frequency of the TMD.

The damping coefficient of the damper in the TMD can be calculated by

$$
c=4 \pi \xi \cdot f \cdot m,
$$

where $c=$ the damping coefficient of the damper and $\xi=$ the damping ratio of the TMD.
To reflect the control level of the TMD on the vibration of NYRB, a formula is proposed to quantify the control efficiency as

$$
\eta=\left|\frac{\alpha-\beta}{\beta}\right|
$$

where $\eta=$ the control efficiency and $\alpha$ and $\beta=$ the peak vertical acceleration in the middle of the bridge deck with and without TMD, respectively.

5.3. Finite Element Modeling of TMD. Since there is no special element for modeling the TMD in ANSYS, the TMD is simulated by the combination of Mass 21 and Combin 14 [27, 28 in this study. The mass blocks of the TMDs are simplified into individual masses and simulated by the element Mass 21. Mass 21 is a single-node element with six degrees of freedom: displacements in the nodal $x, y$, and $z$ directions and rotations about the nodal $x$-, $y$-, and $z$-axes, as shown in Figure 8(a). A different mass and rotary inertia can be assigned to each coordinate direction. The spring and the damper in a TMD are simulated by the element Combin 14 . The element is a uniaxial tension-compression element which has three DOFs at each node, as shown in Figure 8(b). After the proper stiffness and damping coefficient are selected, the functions of the spring and the damper in a TMD can be accurately reflected.

5.4. Initial Static Displacement Induced by the TMDs. The installation of TMDs will cause the changes of the overall layout of initial displacement of NYRB. The displacement variation of the center region of each span induced by the gravities of the TMDs with different masses accompanied by NYRB itself can be seen in Figure 9. Thereinto, the displacement is linear to the mass of TMD, which manifests 


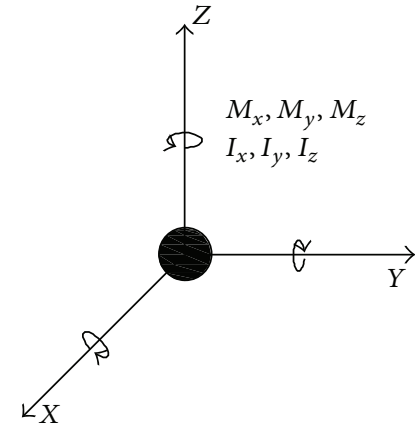

(a) Mass 21

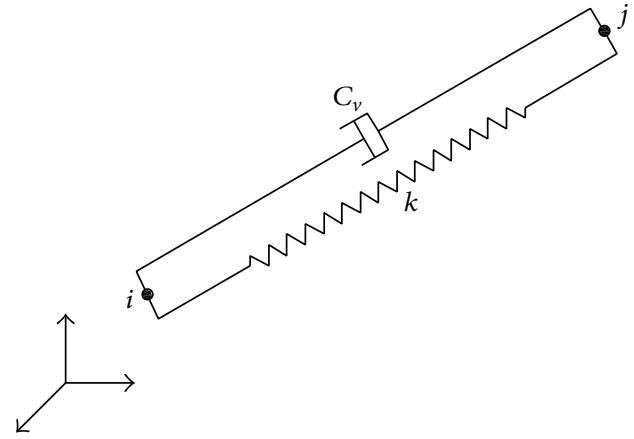

(b) Combin 14

Figure 8: Features of Mass 21 and Combin 14 element.

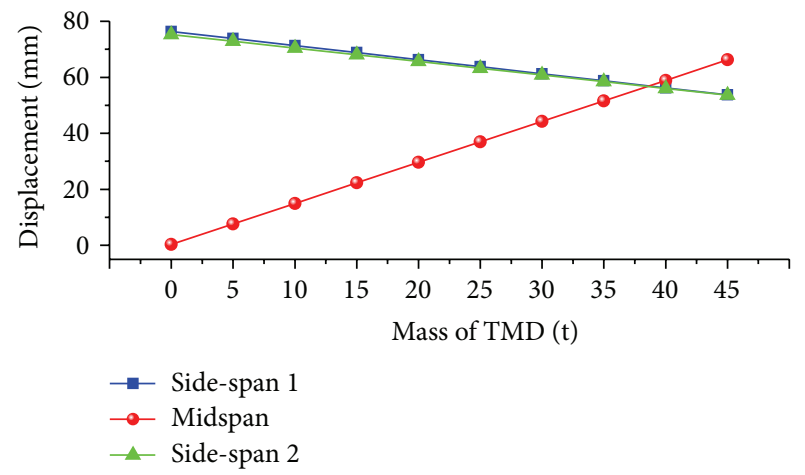

FIGURE 9: Initial static displacement in the middle of each span versus the mass of TMD.

that the whole structure is still in an elastic state even when the mass block of each TMD weighs $45 \mathrm{t}$. The static displacement of each side-span decreases with the augment of the mass of TMD and the displacements of Side-span 1 and Side-span 2 are almost the same, which performs consistently with the structural features of three-span continuous girder bridge. The reduction in the initial static displacement of each side-span is beneficial for the whole structure, but the displacement of Midspan increases sharply with the augment of the mass of TMD. When there is no TMD installed on NYRB, the initial static displacement of Midspan is much smaller than that of each side-span. However, the initial static displacement of Midspan has exceeded that of each side-span when the block of each TMD reaches $40 \mathrm{t}$. Hence, the determination of the mass of TMD should consider its influence on the initial static displacement of Midspan.

5.5. Parametric Analysis on the Control Efficiency of TMD. The mass of the block and the damping ratio are the unique design parameters that greatly influence the control efficiency of TMD on the train-induced vibration of NYRB. Thus the parametric analysis is conducted to quantify the control level of the two influential parameters. The control efficiency of vertical vibration acceleration versus the mass of TMD and the damping ratio of TMD can be seen in Figure 10. In addition, the modal mass of the controlled mode is $4623.5 \mathrm{t}$.
As shown in Figure 10, the control efficiency greatly depends on the mass of TMD. The control efficiency increases sharply with the augment of the mass of TMD when the weight of the block is less than $35 \mathrm{t}$. When the weight of the block is larger than $35 \mathrm{t}$, the growth rate slows down gradually. Meanwhile, the control efficiency will be enhanced by increasing the damping ratio, but the gradient is much smaller than that of the mass of TMD. With regard to the same parameters of TMD for the two cases, the entire control effect of TMD is slightly more prominent in Case 2 than that in Case 1.

In general, the increase of both the mass and the damping ratio has positive impacts on the control efficiency of TMD. It seems that a larger mass of TMD will give a better control performance, but the total mass is limited to the available budget and the augment of the mass will increase the initial static displacement of Midspan. Though the existence of viscous damper can suppress the sensitivity of TMD to the frequency variation of structures, the augment of the damping ratio will inevitably add extra difficulties to the manufacture of the corresponding damper. Therefore, the determination of proper mechanical parameters for a TMD should comprehensively take account of the control efficiency, the economical factor, the manufacture difficulty of the damper, and so forth.

5.6. Determination of the Optimal Parameters for TMD. The parametric analysis reveals the relationship between the design parameters and the control efficiency of TMD, and the selection of design parameters is also closely related to the overall costs, the manufacture difficulty of the TMD, and the static displacement of Midspan. Hence, it is essential to search for an optimal combination of the design parameters to balance all the target factors. In order to realize the optimization in this analysis, the selection of design parameters is transformed into a multiobjective nonlinear optimization problem under constraints.

There are several techniques available to solve the constrained optimization problem [29, 30]. Among them the first-order optimization method is utilized to determine the optimal parameters of the TMD of NYRB. Considering the control efficiency, expenditure of the mass block, and the 


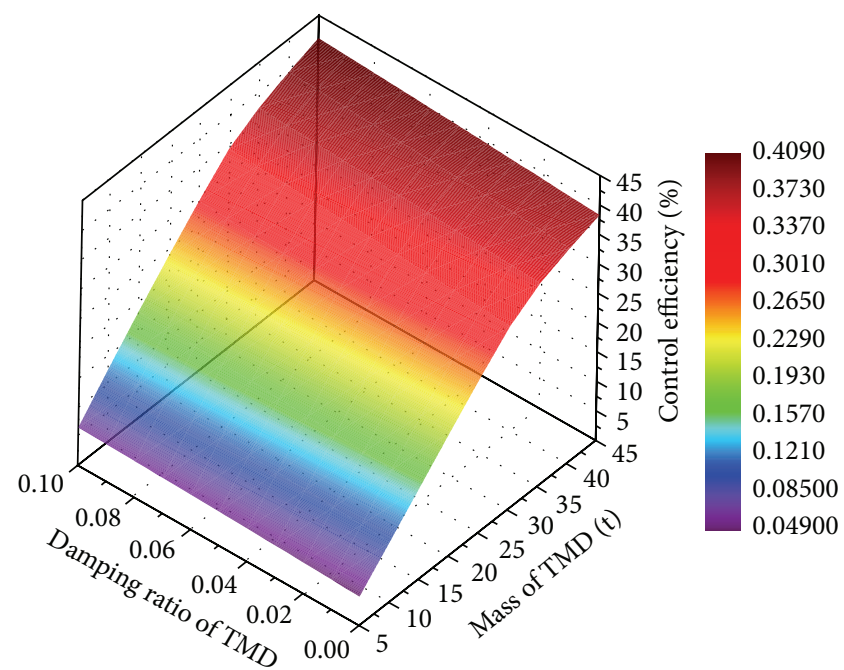

Case 1: single train moving at one side

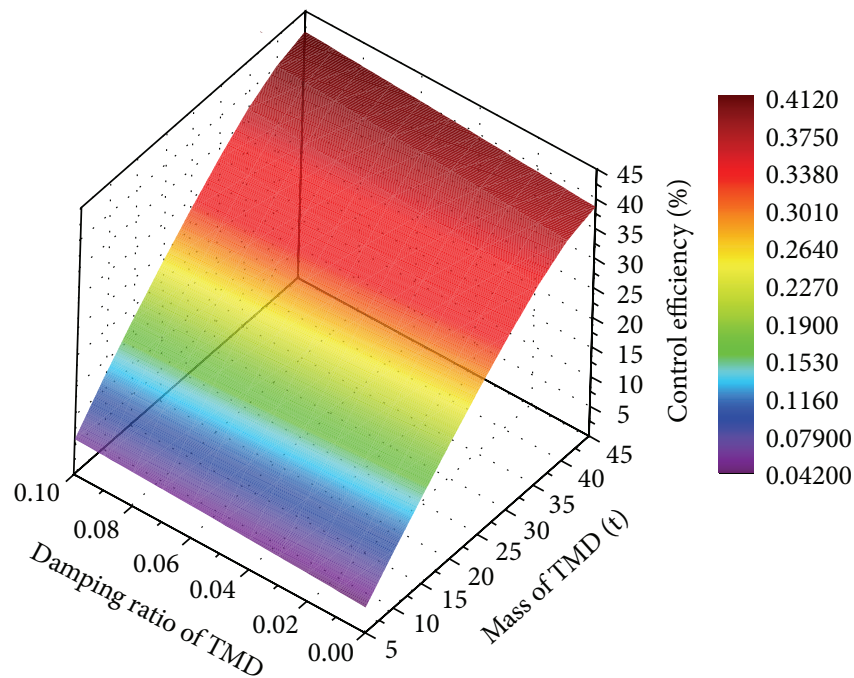

Case 2: two trains moving oppositely

FIGURE 10: Influence of the mass and the damping ratio of the TMD on the control efficiency.

manufacture difficulty of the damper as well as the static displacement of Midspan, an objective function $J$ considering all the above factors is proposed. Then the optimization problem can be formed as follows:

$$
\text { Minimize } J=\frac{\sqrt{E(m) \cdot D(m) \cdot C(\xi)}}{\eta^{2}(m, \xi)}, \quad \eta(m, \xi)>20 \%,
$$

where $E(m)$ = the expenditure evaluating function proportional to the augment of mass of TMD, assuming $E(m)=m$; $D(m)=$ the static displacement evaluating function linear to the augment of mass of TMD, assuming $D(m)$ equals the value in Figure $9 ; C(\xi)=$ the manufacture difficulty function assumed to be exponential correlated with the damping ratio of TMD, assuming $C(\xi)=e^{2 \xi} ; \eta(m, \xi)=$ the control efficiency calculated as $(3) ; \eta_{1}(m, \xi)=$ the control efficiency of Case 1 ; $\eta_{2}(m, \xi)=$ the control efficiency of Case 2. Consider

$$
\eta(m, \xi)=\frac{\eta_{1}(m, \xi)+\eta_{2}(m, \xi)}{2} .
$$

The above procedure is carried out by using the optimization module (/OPT) in ANSYS and the first-order optimization method is applied to obtain the optimal parameters of TMD. The control efficiency is set beyond 20\%. And the lower and upper bounds of the design parameters are the same as those in Figure 10. In order to avoid the local minimum, the zero-order optimization method in the optimization module of ANSYS is employed to validate the optimization results in this study. The optimal parameters of the TMD which can satisfy the objective function are finally determined. Thereinto, the mass of TMD is set as $35 \mathrm{t}$ and the damping ratio is quantified as $5 \%$. Accordingly, the detailed optimal design mechanical parameters are calculated, as shown in Table 3. Large stiffness coefficient and damping coefficient can be realized by the combination of multiple springs and dampers with the same parameters.
TABLE 3: Optimal design mechanical parameters of the TMDs on NYRB.

\begin{tabular}{lcc}
\hline Mass of TMD/t & $\begin{array}{c}\text { Stiffness } \\
\text { coefficient } / \mathrm{kN} \cdot \mathrm{m}^{-1}\end{array}$ & $\begin{array}{c}\text { Damping } \\
\text { coefficient } / \mathrm{t} \cdot \mathrm{s}^{-1}\end{array}$ \\
\hline 35 & 11401.92 & 63.17 \\
\hline
\end{tabular}

5.7. The Control Effect of TMD with Optimal Parameters. After the TMDs with optimal design parameters are installed on NYRB, a comparative study on the train-induced vibration with and without TMD is conducted. The vertical accelerations of each span with and without TMD of the two cases are shown in Figure 11.

As shown in Figure 11, the vertical acceleration of Midspan is prominently decreased and the vertical acceleration of each side-span is reduced to a certain degree. For Side-span 1, the peak vertical acceleration has been reduced from $0.0520 \mathrm{~m} / \mathrm{s}^{2}$ to $0.0384 \mathrm{~m} / \mathrm{s}^{2}$ in Case 1 and from $0.1027 \mathrm{~m} / \mathrm{s}^{2}$ to $0.0640 \mathrm{~m} / \mathrm{s}^{2}$ in Case 2. For Side-span 2, the peak vertical acceleration has been reduced from $0.0669 \mathrm{~m} / \mathrm{s}^{2}$ to $0.0328 \mathrm{~m} / \mathrm{s}^{2}$ in Case 1 and from $0.1509 \mathrm{~m} / \mathrm{s}^{2}$ to $0.0567 \mathrm{~m} / \mathrm{s}^{2}$ in Case 2. The control effect is relatively obvious between $15 \mathrm{~s}$ and $25 \mathrm{~s}$ in Side-span 1, and the vertical acceleration between $15 \mathrm{~s}$ and $30 \mathrm{~s}$ is greatly suppressed by TMD in Side-span 2. With regard to Midspan, the peak vertical accelerations are decreased from $0.1453 \mathrm{~m} / \mathrm{s}^{2}$ to $0.0931 \mathrm{~m} / \mathrm{s}^{2}$ in Case 1 and from $0.3172 \mathrm{~m} / \mathrm{s}^{2}$ to $0.2049 \mathrm{~m} / \mathrm{s}^{2}$ in Case 2 . The corresponding control efficiencies are $35.93 \%$ and $35.40 \%$, respectively. In general, the vertical vibration of Midspan is suppressed effectively during the whole train-passing procedure.

The time histories of the acceleration in the middle of Midspan are transformed into PSDs with Welch transformation, as shown in Figure 12. It is obvious that the energy of structural vibrations near the exciting frequency $(2.761 \mathrm{~Hz})$ is effectively suppressed with TMD. Figure 12 can also verify the 

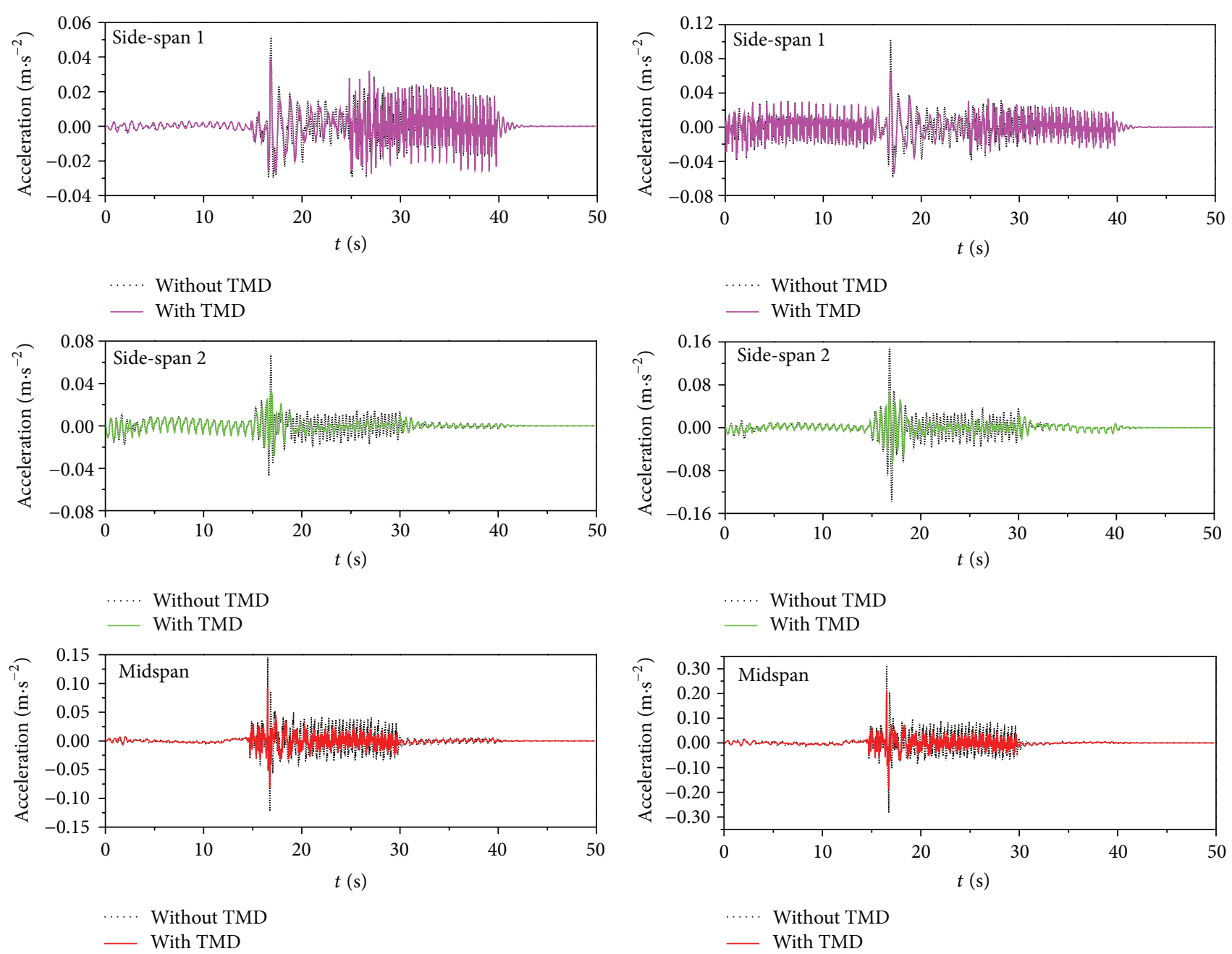

(a) Single train moving at one side

(b) Two trains moving oppositely

FIGURE 11: Train-induced vertical acceleration of NYRB with and without TMD.

prominent contribution of the fourth-order vertical bending mode to the train-induced vibrations. In conclusion, the TMD with reasonable mechanical parameters can effectively suppress the vibration of steel truss bridge subjected to dynamic train loads.

\section{Conclusions}

In this paper, TMD is utilized to suppress the vibrations of a steel truss bridge subjected to dynamic train loads. The dynamic performances of the steel truss bridge when a single train moves at one side and two trains move oppositely are investigated. An objective function considering all the influential factors is proposed and optimal parameters of the TMD are obtained with the first optimization method. The following conclusions can be drawn accordingly.

(1) All of the vertical, lateral, and torsional maximum displacements of each span are small in the two cases. Relatively, the vertical displacement dominates the train-induced displacements of NYRB. The small structural displacements of the bridge under the actions of moving trains show the strong stiffness and sufficient capability of NYRB.

(2) As for the vertical displacements induced by static train loads and dynamic train loads, only a small difference exists between them during the whole procedure. Only when the train is wholly on the bridge, the dynamic vertical displacement fluctuates clearly. However, the deviation between the static and dynamic vertical displacements is still small in this period. Due to the small vertical displacements induced by dynamic train loads, the displacement cannot be chosen as the target to conduct vibration control analysis.

(3) The vertical acceleration of each span especially in Case 2 is prominent. And the vertical acceleration dominates the train-induced vibration of NYRB. Among them, the peak vertical acceleration in the middle of Midspan is much larger than that of Sidespan 1 and Side-span 2. 


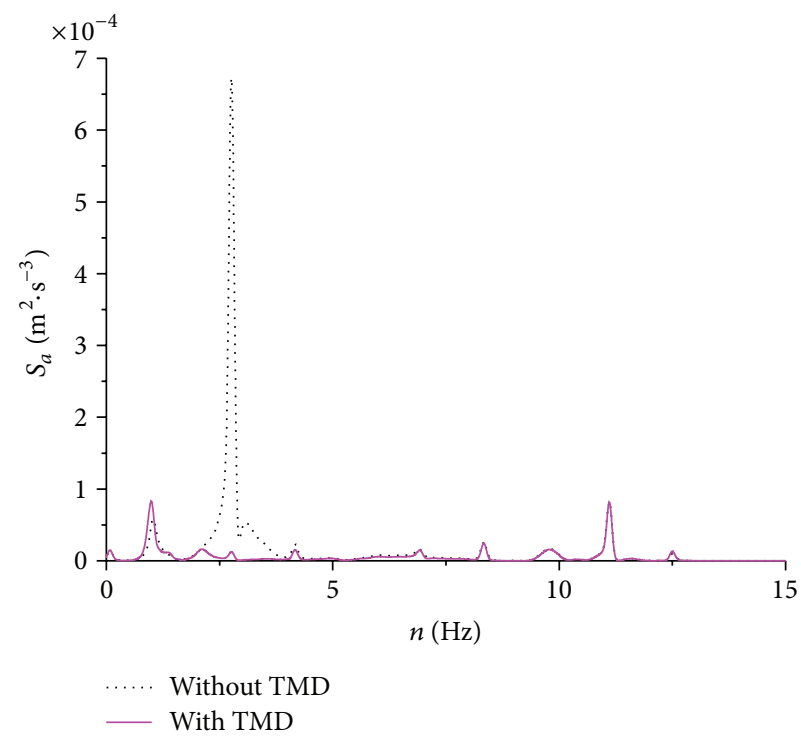

(a) Single train moving at one side

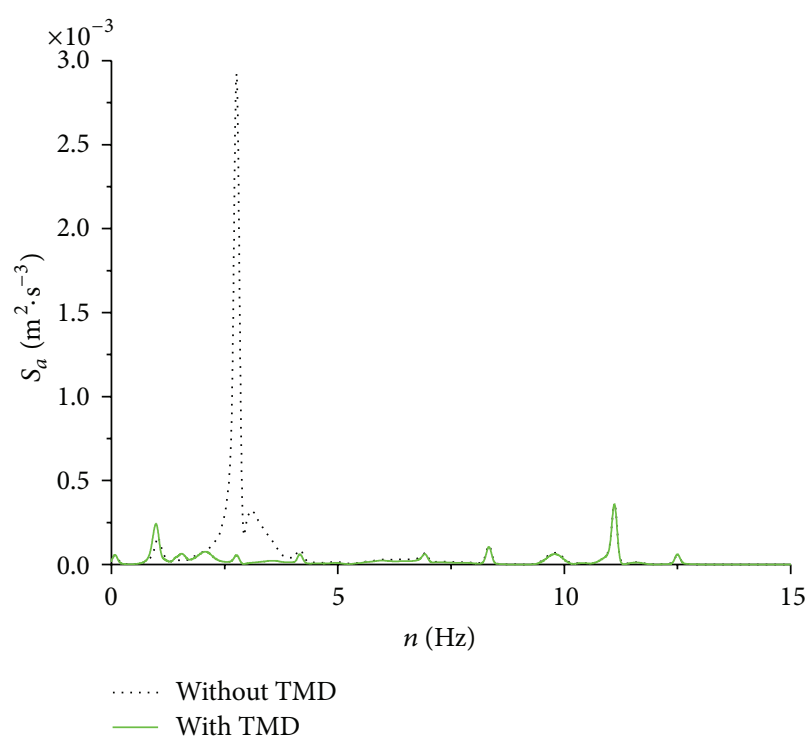

(b) Two trains moving oppositely

FIGURE 12: Power spectral density of vertical acceleration of Midspan with and without TMD.

(4) The control efficiency of TMD increases sharply with the augment of the mass of TMD when the weight of the mass block is less than $35 \mathrm{t}$. When the weight of the mass block is larger than $35 \mathrm{t}$, the growth rate of the control efficiency begins to become smaller. Meanwhile, the control efficiency of TMD will be enhanced by increasing the damping ratio, but the increasing gradient is much smaller than that of the mass of TMD. In general, the increase of either the mass or the damping ratio has positive influence on the control efficiency of TMD.

(5) Taking the control efficiency, expenditure of TMDs, TMD-induced static displacement of the bridge, and the manufacturing difficulty of damping of different magnitude into account, the optimal design parameters of the TMD are finally determined with the first optimization method. With the optimal design parameters, the peak vertical acceleration of each side-span is obviously reduced; the peak vertical acceleration of Midspan is decreased from $0.1453 \mathrm{~m} / \mathrm{s}^{2}$ to $0.0931 \mathrm{~m} / \mathrm{s}^{2}$ in Case 1 and from $0.3172 \mathrm{~m} / \mathrm{s}^{2}$ to $0.2049 \mathrm{~m} / \mathrm{s}^{2}$ in Case 2, and corresponding control efficiencies are $35.93 \%$ and $35.40 \%$, respectively.

(6) The PSDs of vertical acceleration of Midspan reveal that the energy of structural vibrations near the exciting frequency $(2.761 \mathrm{~Hz})$ is effectively suppressed with TMD, which can also reflect the contribution of the fourth-order vertical bending mode to the train-induced vibrations. In conclusion, the TMD with reasonable mechanical parameters can effectively suppress the vibration of long-span steel truss bridge subjected to dynamic train loads.

\section{Conflict of Interests}

The authors declare that there is no conflict of interests regarding the publication of this paper.

\section{Acknowledgments}

This work is supported by the Major State Basic Research Development Program of China (973 Program) (Grant no. 2015CB060000), the National Science Foundation of China (Grant nos. 51378111 and 51438002), the Fok Ying-Tong Education Foundation for Young Teachers in the Higher Education Institutions of China (Grant no. 142007), the Program for New Century Excellent Talents in University of Ministry of Education of China (Grant no. NCET-130128), and the Fundamental Research Funds for the Central Universities (Grant no. 2242012R30002). These supports are gratefully acknowledged.

\section{References}

[1] Y. Fujino and M. Abe, "Dynamic response of concrete railway bridges," in International Association for Bridge and Structural Engineering Proceedings, pp. 53-68, 1993.

[2] L. Frýba, "A rough assessment of railway bridges for high speed trains," Engineering Structures, vol. 23, no. 5, pp. 548-556, 2001.

[3] J. Li, M. Su, and L. Fan, "Vibration control of railway bridges under high-speed trains using multiple tuned mass dampers," Journal of Bridge Engineering, vol. 10, no. 3, pp. 312-320, 2005.

[4] Y.-B. Yang, J.-D. Yau, and L.-C. Hsu, "Vibration of simple beams due to trains moving at high speeds," Engineering Structures, vol. 19, no. 11, pp. 936-943, 1997.

[5] R. J. McNamara, “Tuned mass dampers for buildings," Journal of Structural Division, vol. 103, no. 9, pp. 1785-1798, 1977. 
[6] R. W. Luft, “Optimal tuned mass dampers for buildings," Journal of Structural Division, vol. 105, no. 12, pp. 2766-2772, 1979.

[7] L. A. Bergman, D. M. McFarland, J. K. Hall, E. A. Johnson, and A. Kareem, "Optimal distribution of tuned mass dampers in wind-sensitive structures," in Proceedings of the 5th International Conference on Structural Safety and Reliability (ICOSSAR '89), pp. 95-102, ASCE, New York, NY, USA, August 1989.

[8] H.-N. Li and X.-L. Ni, "Optimization of non-uniformly distributed multiple tuned mass damper," Journal of Sound and Vibration, vol. 308, no. 1-2, pp. 80-97, 2007.

[9] T.-H. Yi, H.-N. Li, and M. Gu, "Experimental assessment of high-rate GPS receivers for deformation monitoring of bridge," Measurement: Journal of the International Measurement Confederation, vol. 46, no. 1, pp. 420-432, 2013.

[10] G. B. Warburton, "Optimum absorber parameters for minimizing vibration response," Earthquake Engineering \& Structural Dynamics, vol. 9, no. 3, pp. 251-262, 1981.

[11] Y. L. Xu, K. C. S. Kwok, and B. Samali, "Control of wind-induced tall building vibration by tuned mass dampers," Journal of Wind Engineering and Industrial Aerodynamics, vol. 40, no. 1, pp. 1-32, 1992.

[12] Y. Fujino and M. Abe, "Design formulas for tuned mass dampers based on a perturbation technique," Earthquake Engineering \& Structural Dynamics, vol. 22, no. 10, pp. 833-854, 1993.

[13] K. K. F. Wong, "Seismic energy dissipation of iInelastic structures with tuned mass dampers," Journal of Engineering Mechanics, vol. 134, no. 2, pp. 163-172, 2008.

[14] H.-C. Kwon, M.-C. Kim, and I.-W. Lee, "Vibration control of bridges under moving loads," Computers and Structures, vol. 66, no. 4, pp. 473-480, 1998.

[15] J. F. Wang, C. C. Lin, and B. L. Chen, "Vibration suppression for high-speed railway bridges using tuned mass dampers," International Journal of Solids and Structures, vol. 40, no. 2, pp. 465-491, 2003.

[16] C. C. Lin, J. F. Wang, and B. L. Chen, "Train-induced vibration control of high-speed railway bridges equipped with multiple tuned mass dampers," Journal of Bridge Engineering, vol. 10, no. 4, pp. 398-414, 2005.

[17] R. Willis, "The effect produced by causing weights to travel over elastic bars," Report of Commissioners appointed to inquire into the application of iron to railway structures, Appendix , H.M. Stationery Office, London, UK, 1847.

[18] A. Kriloff, "Über die erzwungenen Schwingungen von gleichförmigen elastischen Stäben," Mathematische Annalen, vol. 61, no. 2, pp. 211-234, 1905.

[19] S. Timoshenko, "On the transverse vibrations of bars of uniform cross section," Philosophical Magazine, vol. 43, pp. 125-131, 1922.

[20] J. Vellozzi, "Vibration of suspension bridges under moving loads," Journal of Structural Engineering, vol. 93, no. 4, pp. 123$138,1967$.

[21] P. K. Chatterjee, T. K. Datta, and C. S. Surana, "Vibration of continuous bridges under moving vehicles," Journal of Sound and Vibration, vol. 169, no. 5, pp. 619-632, 1994.

[22] X.-H. He, Z.-W. Yu, and Z.-Q. Chen, "Finite element model updating of existing steel bridge based on structural health monitoring," Journal of Central South University of Technology, vol. 15, no. 3, pp. 399-403, 2008.

[23] Swanson Analysis Systems (SASI), ANSYS User's Manual, Version 8.0, Swanson Analysis Systems (SASI), Houston, Pa, USA, 2004.
[24] T.-H. Yi, H.-N. Li, and M. Gu, "A new method for optimal selection of sensor location on a high-rise building using simplified finite element model," Structural Engineering \& Mechanics, vol. 37, no. 6, pp. 671-684, 2011.

[25] H. Wang, R. Zhou, Z. Zong, C. Wang, and A. Li, "Study on seismic response control of a single-tower self-anchored suspension bridge with elastic-plastic steel damper," Science China Technological Sciences, vol. 55, no. 6, pp. 1496-1502, 2012.

[26] The MathWorks, MATLAB \& SIMULINK Release Notes for R2010b, The MathWorks, Natick, Mass, USA, 2010.

[27] M. Gu, S. R. Chen, and C. C. Chang, "Parametric study on multiple tuned mass dampers for buffeting control of Yangpu Bridge," Journal of Wind Engineering and Industrial Aerodynamics, vol. 89, no. 11-12, pp. 987-1000, 2001.

[28] T. H. Nguyen, I. Saidi, E. F. Gad, J. L. Wilson, and N. Haritos, "Performance of distributed multiple viscoelastic tuned mass dampers for floor vibration applications," Advances in Structural Engineering, vol. 15, no. 3, pp. 547-562, 2012.

[29] A. K. Agrawal and J. N. Yang, "Optimal placement of passive dampers on seismic and wind-excited buildings using combinatorial optimization," Journal of Intelligent Material Systems and Structures, vol. 10, no. 12, pp. 997-1014, 1999.

[30] H. Wang, A. Li, C. Jiao, and B. F. Spencer, "Damper placement for seismic control of super-long-span suspension bridges based on the first-order optimization method," Science China Technological Sciences, vol. 53, no. 7, pp. 2008-2014, 2010. 


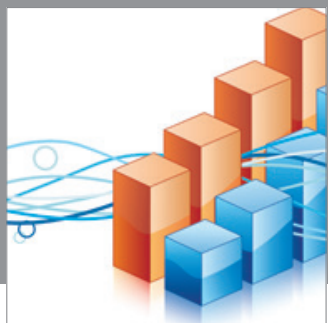

Advances in

Operations Research

mansans

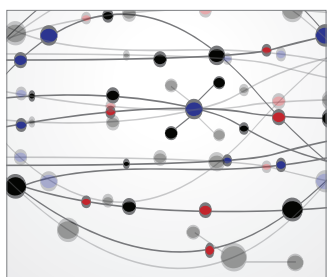

The Scientific World Journal
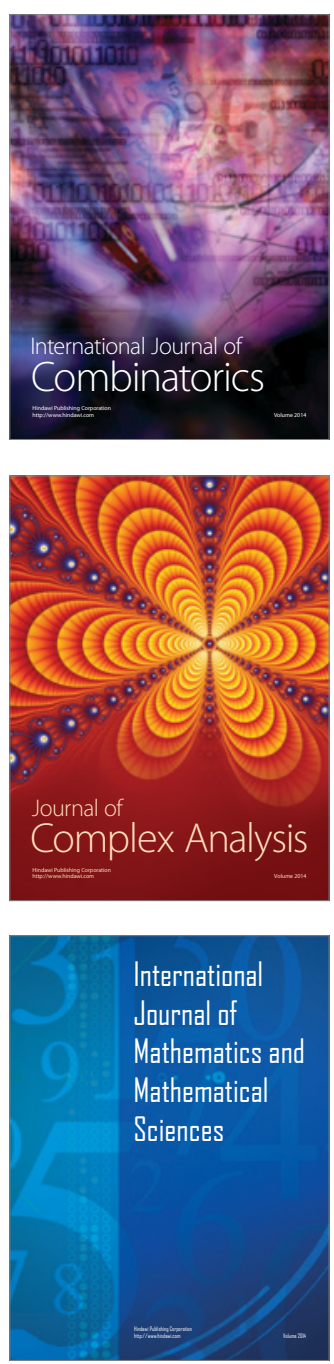
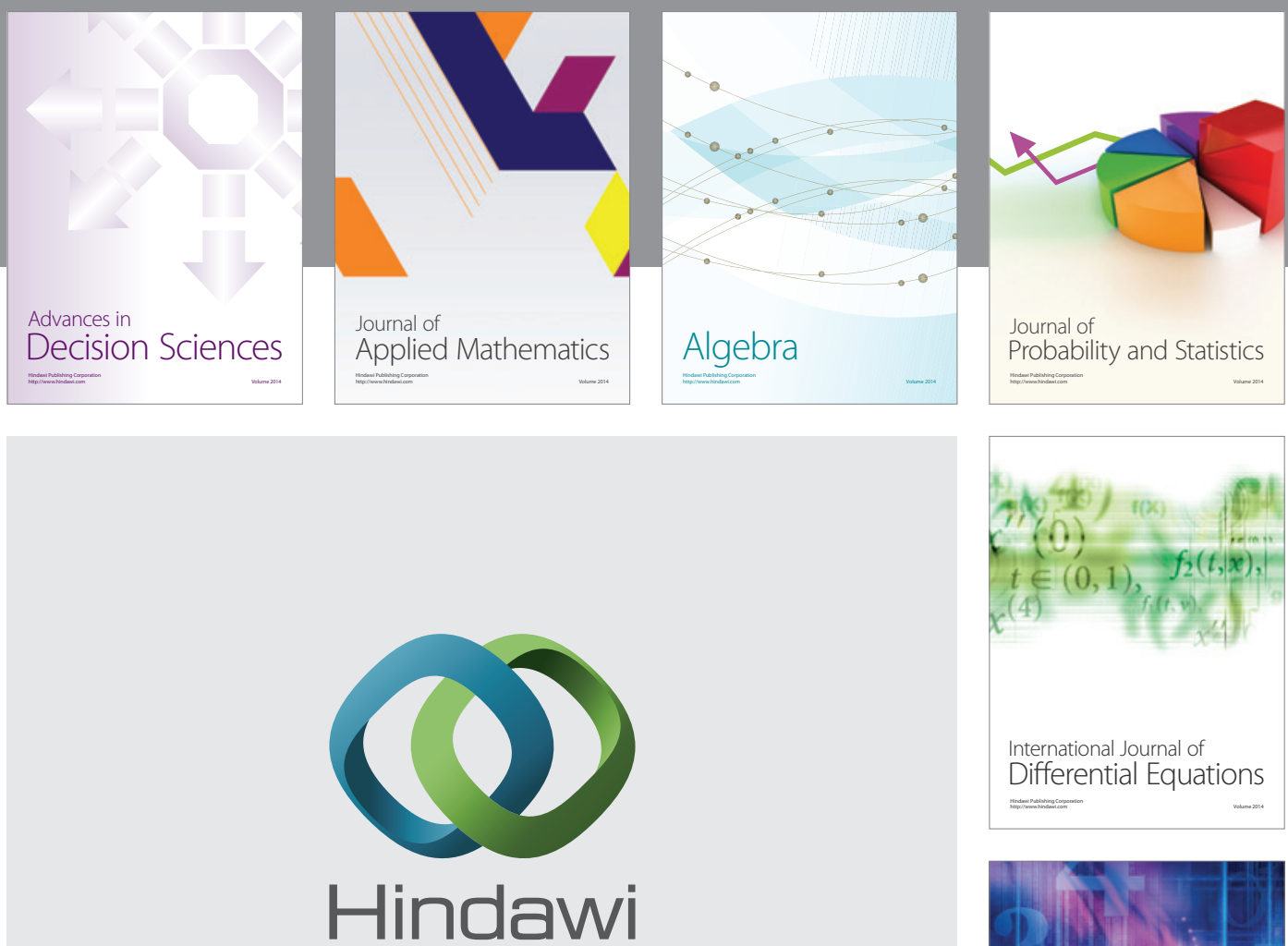

Submit your manuscripts at http://www.hindawi.com
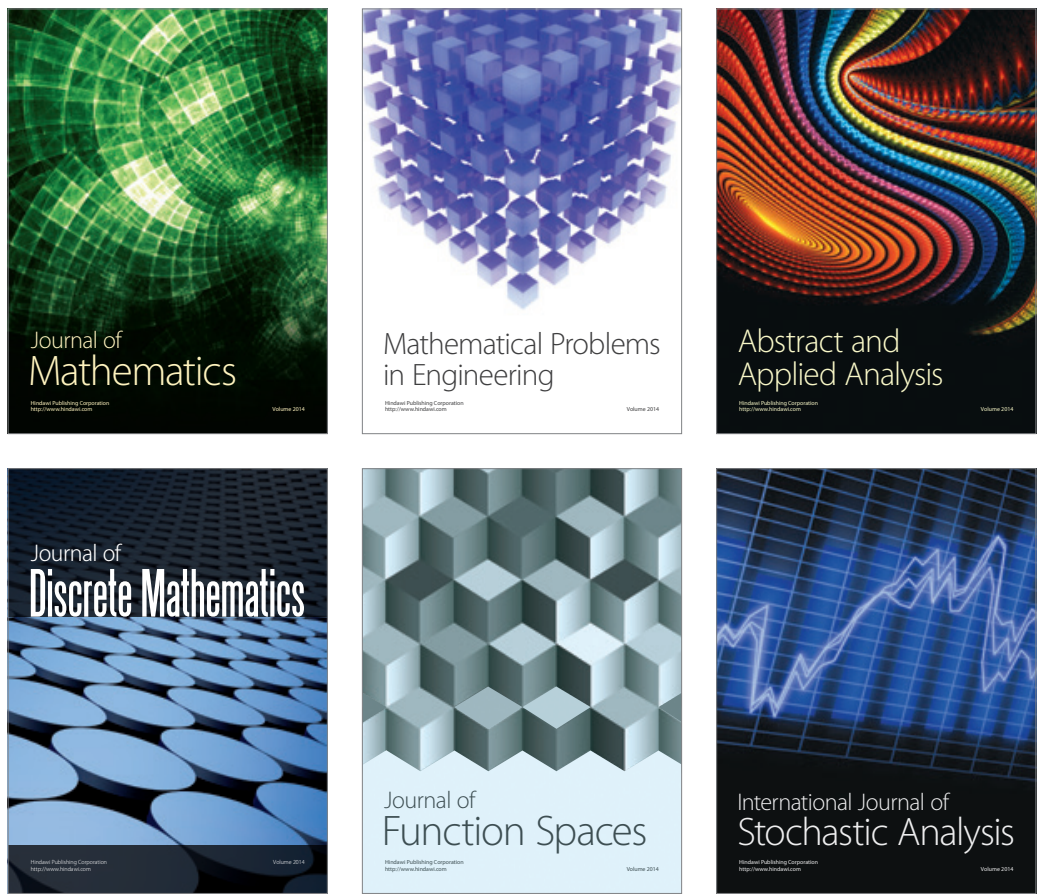

Journal of

Function Spaces

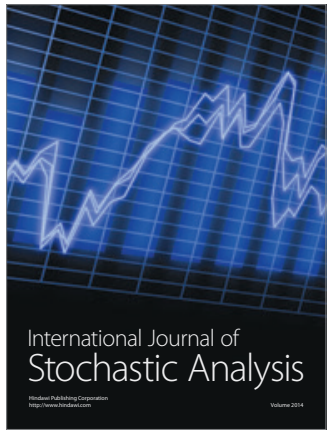

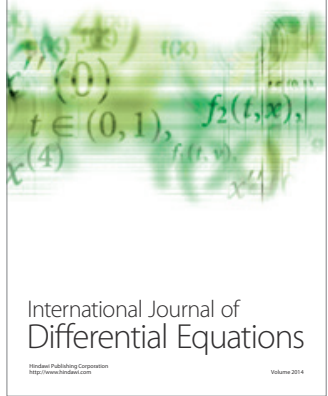
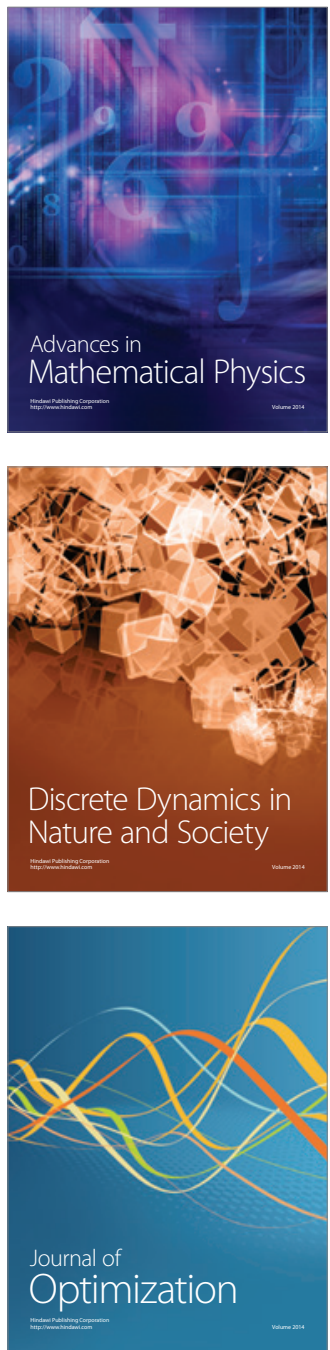